\title{
A QUALITATIVE EXPLORATION OF FRUSTRATION FROM THE PERSPECTIVE OF EMERGING ADULTS
}

\author{
Aaliya Zaka ${ }^{1 *}$, Iffat Rohail ${ }^{2}$, Andleeb Akhtar ${ }^{3}$, Hajra Aman ${ }^{4}$, Touseef Khalid ${ }^{5}$ \\ ${ }^{1 *}$ Ph.D., Scholar, Department of Psychology, Foundation University, Pakistan; ${ }^{2}$ Professor, Department of Psychology, \\ Foundation University, Islamabad, Pakistan; ${ }^{3}$ Lecturer Psychology, The University of Haripur, Haripur, Pakistan \& Ph.D., \\ Scholar, Department of Psychology, Foundation University, Islamabad, Pakistan; ${ }^{4}$ Ph.D., Scholar, Department of \\ Psychology, Foundation University, Islamabad, Pakistan; ${ }^{5} \mathrm{Ph} . \mathrm{D} .$, Scholar, Department of Psychology, Foundation \\ University, Islamabad, Pakistan. \\ Email: ${ }^{1 *}$ aaliyazaka@yahoo.com, ${ }^{2}$ iffat.rohail@ fui.edu.pk, ${ }^{3}$ andleebmalik81@yahoo.com, ${ }^{4}$ hajra_sarfraz@ hotmail.com, \\ 5touseef.09@gmail.com
}

Article History: Received on $15^{\text {th }}$ April 2021, Revised on $25^{\text {th }}$ April 2021, Published on $1^{\text {st }}$ May 2021

\begin{abstract}
Purpose: The present study was aimed to explore the phenomena of frustration from the perspective of emerging adults.

Methodology: Qualitative research design was followed in the study. Data was collected through semi-structured interviews. The sample consisted of 69 emerging adults ( 33 males, 36 females) aged from 18 years to 25 years. A convenient sampling technique was used to collect the data. The data was collected from different universities of Rawalpindi and Islamabad, Pakistan; An open-ended questionnaire was developed to explore the concept of frustration for conducting semi-structured interviews. Content analysis was employed to analyze the data.
\end{abstract}

Main Findings: Analysis of the transcripts revealed one main theme; emotions related to frustration, and three subthemes; Affective emotions, Cognitive styles, and Behavioral emotions.

Implications/Applications: The current study results highlight the importance of considering how young adults understand their conditions to help them regain functioning status and prevent missed developmental milestones for physicians dealing with emerging adults experiencing frustration. Besides, this research indicates to policymakers that the lack of optimism associated with anxiety disorders and inadequate access to and fragmentation of mental health services can substantially hinder these young adults' capacity to receive consistent, high-quality care.

Novelty/Originality of this study: Many quantitative researches have investigated the reaction to frustration among adolescents. Emotions of frustration are different according to the situation. In literature, no qualitative study found that investigated this phenomenon in emerging adults. So this study was intended to explore the construct of frustration qualitatively.

Keywords: Emerging Adults, Frustration, Affective Emotions, Content Analysis, Behavioral Emotions.

\section{INTRODUCTION}

Emerging adulthood is a challenging stage of life for any young individual and accompanied by irresistible frustrations. The transition period from age 18 to 30 has reverberation, an alteration from the dependency of adolescence to chores and independence of young adulthood (Boll, 2017). Arnett (2000) identified it as the stage of emerging adulthood between adolescence and young adulthood because of the changes in society. These changes have enhanced the transition period to young adulthood, from 18 years of age to 29 years and even more. It has some features, including the age of exploring identity, age of life instability, age of being between adolescence and adulthood, age of self-focused, and the following opportunities for the future. In this transition, the young individuals feel a state of being stuck, similar to a failure. The term "failure to launch" is a way to describe the frustration of young people that seem and feel to be unable to move onwards and attain significant expected milestones of their age (Boll, 2017). Some young individuals are unable to make this transition within time. This sense of ineffectiveness is accompanied or can be fueled by underlying mental health problems and frustration. The very first step is to understand is the growing frustration of emerging adults. Under this frustration, the emerging adults can cope with their transition. However, the frustration of some emerging adults can lead them to mental health problems.

Frustration is a positive and helping process that facilitates a person to control their lives, cope with their problems, formulate informed choices, and decision-making about their lives. Frustration has been explained from perspectives of Sociology (Morrall, 1996), social work (Stevenson \& Parsloe, 1993), and Psychology (Zimmwerman \& Rappaport, 1988). Previous research (Rani \& Deswal, 2015; Johansen et al., 2020) had clear evidence that frustration is a very important construct to measure and explore among emerging adults for good mental health and for spending better life. There is a need to investigate the knowledge gap for understanding frustration meanings to emerge adults and their view of frustration. This would provide valuable insight into their needs ( 
Frustration is a term coined commonly within Child and Adolescent Mental Health Services (CAMHS) (2006). However, the concept of frustration from a child and adolescent perspective are well documented (Bhutia, 2014; Chatterjee, 2016; Dave, 2013; Bernard \& Eilis, 2006; Kakkar, 2015; Kashyp, 1989; Sharma, 1992; Ozer \& Schwartz, 2020), lacking a relative understanding of construct from the perspective of the emerging adult. The present study is aimed to investigate how the concept of frustration applies to emerging adults.

Qualitative researches have studied understanding of experiences of the concept of frustration from a stance of emerging adults. Qualitative studies have permitted vast insight and understanding into complicated human behaviour compared to surveys and different quantitative measures of personal experiences (Denzin \& Lincoln, 2000; Parmenter, Galliher, Yaugher, \& Maughan, 2020). Izard (1993) proposed four components of the emotion model (subjective experience, physiological response, social expressive, purposive) for studying and understanding frustration employed in this study. Interviews were conducted to analyze the participants' experience of frustration. Content analysis was employed to transcribe the interviews

\section{The rationale of the Study}

Previous literature revealed that most of the work on frustration had been done in India and the West. Although the concept of frustration from a child and adolescent perspective was well documented (Bhutia, 2014; Chatterjee, 2016; Dave, 2013; Bernard \& Eilis, 2006; Kakkar, 2015; Kashyp, 1989; Sharma, 1992), there was no research found in the literature to study the emerging adults' perspective. So the current research is conducted to study how the concept of frustration applies to emerging adults.

\section{Research Question}

This discussion leads to a question here

- What is the indigenous perspective of frustration among emerging adults?

\section{LITERATURE REVIEW}

The new stage of explorative and experimental adult life is closely related to student life (Arnett, 2016). This extended period of role exploration and limited responsibilities was made possible by demographic changes that increased economic and educational opportunities for young people, particularly in Western and urban contexts. Indeed, the flexibility and autonomy available to many young people pursuing higher education allow them to engage in a variety of life opportunities and personal development. The proposal for the emerging adult community has five different characteristics: identity exploration, instability, self-centering, feeling between them, and opportunities/optimism (Arnett, 2016). In relation to the flexibility of one or more years of gap between high school completion and tertiary education, the emerging adulthood phenomenon has been identified among Danes (Arnett \& Padilla-Walker, 2015; Arnett, 2016). These years of the gap are usual for exploring and maturing through temporary work, non-formal adult education, voluntary activities, and worldwide travel. Danish young adults will also move from their parents' homes earlier, live together before marriage, and become parents later than other European children (Arnett \& Padilla Walker, 2015). In relation to the flexibility to take one or more years from secondary school completion to tertiary education compared with other European children the emergent adolescent phenomenon has been identified among Danes (Arnett, 2016; Arnett \& Padilla-Walker, 2015). Education is free for all Danish citizens within the Danish welfare system and students are awarded housing and food grants - making them largely financially independent. Previously, an additional student year was provided if they decided to change or expand their field of study. Furthermore, Danish students enjoyed an extremely flexible structure in the university until recently, allowing delays in studying time and allowing student years to undertake other activities. This participation in student employment, voluntary work, and political activities can also play an important role in developing self-conception and citizenship, amongst other commitments (illauer, 2020).

Ozer and Schwartz (2020) stated that the underlying extrinsic and internal motivation lies in five types of regulation. Firstly, less autonomous behaviors are considered to be regulated externally. Such behaviour, such as compliance with or evasion of punishment, is based upon reasons outside the individual. The second type of regulation, called introjected regulation, is a relatively controlled type of regulation that can lead to behavior that improves self-reliance or prevents culpability or anxiety. It indexes behaviors that have been introduced but which are not approved by the individual because of foreign reasons. The third type of regulation is known as the regulatory system. This style of regulation deliberately reflects the evaluation of a behavioral objective that is therefore accepted as personal. That is, although the behavior can be performed to meet external requirements, it can be motivated somewhat internally. The fourth style of regulation is referred to as an integrated regulation, where the regulations are incorporated into themselves in accordance with the other values of the person. The fifth type of regulation is comprehensive and is linked to behaviour (Ozer \& Schwartz, 2020).

The theory of self-determination (SDT) has become popular for examining questions of motivation in many contexts. It is not surprising, given the nature and function of the motive in conjunction with the psychological basis from which the 
approach to human development proposed within the SDT takes into account. The motivation varies from more controlled to fully self-determined processes, which have beneficial consequences, including persistence in tasks and eudemonic wellbeing (Costa et al., 2017).

In the context of a cross-cultural validation (United States, China, Peru, and Belgium), Chen et al. (2015) found evidence supporting a six-factor BPNSFS structure, indicating six different dimensions: autonomy satisfaction, relatedness, and competence and frustration. Similarly, the six-factor model, including in an Italian sample, was recently supported by Costa et al. (2018).

The model emphasizes that all three requirements are fulfilled and frustrated separately and therefore, although correlated, psychometrically they are separated and provide a unique contribution. In addition, this model suggests two correlated factors: satisfaction and frustration from the same necessity. While poor satisfaction impairs the growth and well-being of individuals, frustration with these requirements would cause serious illness and psychopathology (Vansteenkiste \& Ryan, 2013). For example, this idea suggests that those with little contact with friends (less satisfaction with connectivity) can have less vitality for social events, but people who are actively rejected or excluded by friends (frustration with relationships) may experience depression or other severe problems (Vansteenkiste \& Ryan, 2013; Liga et al., 2018).

Many studies have shown that parental psychological control is positively related to psychological distress, negatively related to scholastic achievement and academic competence, and increases the risk of developing LH. In terms of frustration intolerance, clinical studies have shown an association with procrastination and behavioral avoidance. Furthermore, frustration intolerance is a significant predictor of depression and trait anxiety. Many studies have shown that the psychological parental control has a positive relation to the psyche, is negative to academic achievement, and increases the risk of LH. Clinical studies have demonstrated a link between degradation and behavioral avoidance concerning frustration intolerance. In addition, frustration intolerance is a major predictor of depression and anxiety about traits. Even when research has studied the link between LH, MO, psychological control, and school performance, in the relation between perceived psychological control and LH and MO the potential role of mediation of frustration intolerance has not ever been studied (Caterina et al., 2018; Santurio et al., 2020; Aydın \& Michou, 2020; Vansteenkiste \& Ryan, 2013; Liga et al., 2018).

\section{METHODS}

\section{Sample}

To explore the concept of frustration 69 emerging adults ( 33 males, 36 females) aged 18 to 25 years were taken from the different universities of Rawalpindi and Islamabad. There is a harmony towards using a small sample size in qualitative research for detailed analysis and producing rich understanding (Reid et al., 2005).

\section{Instrument}

An open-ended questionnaire was developed to explore the concept of frustration among emerging adults. The researcher and supervisor decided that three questions might be given to respondents. The questionnaire was developed to help participants' for a personal narrative in their own words.

\section{Ethical Consideration}

Participants were given written information about this research. From each participant's participation, written consent was obtained.

\section{Procedure}

A common method used in qualitative studies is the Interview method (Smith \& Osborn, 2008). A semi-structured interview was conducted in this study to get the emerging adults' descriptive reports of their frustration experience and related emotion of frustration (Izard, 1993). Formal consent was acquired before the interview with the help of informed consent. The interview was designed to help participants formulate a personal narration by using their own words. The questions were neutral and open-ended. An example of one of these is "what is frustration"? Although the questions were pre-planned, the researcher allowed the question to flow naturally, based on information provided by the respondents. Each interview took about an average time of 10 to 15 minutes. Thus participants were facilitated to talk with the least interruption and constraint from the interviewer. The researcher documented the responses of each participant in the form of an interview transcript. The researcher tried to establish a good rapport and trust to create a relaxed atmosphere. The participants were probed in the interview.

Table 1: Demographic characteristics of the participants ( $\mathrm{N}=69)$

\begin{tabular}{llll}
\hline Demographics & Group & $\boldsymbol{F}$ & \% \\
\hline Gender & Male & 33 & 47.83 \\
\hline
\end{tabular}




\begin{tabular}{llll}
\hline & Female & 36 & 52.17 \\
\hline Education Level & Graduate & 47 & 68.12 \\
\hline & Post Graduate & 22 & 31.88 \\
\hline Age & $18-21$ & 40 & 57.97 \\
\hline & $22-25$ & 29 & 42.03 \\
\hline
\end{tabular}

\section{Data Analysis}

Data obtained from interviews were analyzed by using content analysis outlined by Howitt (2010). With an orderly step-bystep method, interviews' verbatim was transcribed. The researcher analyzed transcripts one by one. Initially, the researcher read and re-read every transcript minimum of 5 times for becoming familiar with each account. The first reading was aimed to become familiar with the young individuals' experiences and perceptions of frustration. The second and third readings were dedicated to identifying common and repeated themes relevant to the participants' frustration experience. To identify themes and note connections, fourth and fifth readings were accomplished. Related items were retained evolved themes were noted, and then rearranged into initial lists.

During data analysis, the main theme, sub-themes, and initial themes were noted. Then themes were given to the group, and comparisons were made. The final list of sub-themes was developed for each interview. The results were then given to three experts who confirmed the analysis reliability. Themes drawn transcripts were verified by this procedure, and the connection with the quotes was also verified.

\section{RESULTS}

Analysis of the transcripts revealed one main theme, three sub-themes, and many initial themes. The main theme was an emotion of frustration. From this main theme, sub-themes were identified. They are presented in Table 2.

Table 2: Frequencies and percentages of responses by interviews on each initial themes $(n=69)$

\begin{tabular}{|c|c|c|c|c|c|}
\hline \multirow[t]{2}{*}{ Main theme } & \multirow[t]{2}{*}{ Sub Themes } & \multirow[t]{2}{*}{ Initial Themes } & \multicolumn{3}{|c|}{ Frequency (\%) } \\
\hline & & & $\begin{array}{l}\text { Female } \\
(n=36)\end{array}$ & $\begin{array}{l}\text { Male } \\
(n=33)\end{array}$ & $\begin{array}{l}\text { Total } \\
(N=69)\end{array}$ \\
\hline \multirow[t]{28}{*}{ Emotions Related to Frustration } & \multirow[t]{13}{*}{ Affective Emotions } & Irritation & $25(69 \%)$ & $31(93 \%)$ & $56(81 \%)$ \\
\hline & & Helplessness & $20(55 \%)$ & $9(27 \%)$ & $29(42 \%)$ \\
\hline & & Disappointment & $23(63 \%)$ & $21(63 \%)$ & $44(63 \%)$ \\
\hline & & Sadness & $19(52 \%)$ & $11(33 \%)$ & $30(43 \%)$ \\
\hline & & Stress & $15(41 \%)$ & $10(30 \%)$ & $25(36 \%)$ \\
\hline & & Disturbance & $34(94 \%)$ & $21(63 \%)$ & $55(79 \%)$ \\
\hline & & Hurts & $20(55 \%)$ & $9(27 \%)$ & $29(42 \%)$ \\
\hline & & Crippledness & $3(.08 \%)$ & $2(.06 \%)$ & $5(7 \%)$ \\
\hline & & Pressurized & $27(75 \%)$ & $13(39 \%)$ & $40(57 \%)$ \\
\hline & & Annoyed & $35(97 \%)$ & $20(60 \%)$ & $55(79 \%)$ \\
\hline & & Worried & $36(100 \%)$ & $19(57 \%)$ & $55(79 \%)$ \\
\hline & & Anxious & $34(94 \%)$ & $21(63 \%)$ & $55(79 \%)$ \\
\hline & & Hopelessness & $19(52 \%)$ & $10(30 \%)$ & $29(42 \%)$ \\
\hline & \multirow[t]{8}{*}{ Cognitive Styles } & Loss of Interest & $15(41 \%)$ & $9(27 \%)$ & $24(34 \%)$ \\
\hline & & Mental pressure & $25(69 \%)$ & $19(57 \%)$ & $44(63 \%)$ \\
\hline & & Upset & $32(88 \%)$ & $10(30 \%)$ & $42(69 \%)$ \\
\hline & & Negative Thinking & $23(63 \%)$ & $15(45 \%)$ & $38(55 \%)$ \\
\hline & & Loss of Confidence & $25(69 \%)$ & $15(45 \%)$ & $40(57 \%)$ \\
\hline & & Tension & $30(83 \%)$ & $25(75 \%)$ & $55(79 \%)$ \\
\hline & & Conflict & $34(94 \%)$ & $20(60 \%)$ & $54(78 \%)$ \\
\hline & & Overthinking & $32(88 \%)$ & $25(75 \%)$ & $57(82 \%)$ \\
\hline & \multirow[t]{7}{*}{ Behavioral Emotions } & Anger & $29(80 \%)$ & $11(33 \%)$ & $40(57 \%)$ \\
\hline & & Instability & $19(52 \%)$ & $10(30 \%)$ & $29(42 \%)$ \\
\hline & & Crying Spells & $25(69 \%)$ & $5(15 \%)$ & $30(43 \%)$ \\
\hline & & Inability & $36(100 \%)$ & $19(57 \%)$ & $55(79 \%)$ \\
\hline & & Boredom & $7(19 \%)$ & $5(15 \%)$ & $12(17 \%)$ \\
\hline & & Fear & $20(55 \%)$ & $5(15 \%)$ & $25(36 \%)$ \\
\hline & & Withdrawal & $25(69 \%)$ & $7(21 \%)$ & $32(46 \%)$ \\
\hline
\end{tabular}




\begin{tabular}{llll} 
Insecurity & $22(61 \% 0$ & $14(42 \%)$ & $36(52 \%)$ \\
\hline Aggression & $35(97 \%)$ & $26(78 \%)$ & $61(88 \%)$ \\
\hline Lack of tolerance & $15(41 \%)$ & $9(27 \%)$ & $24(34 \%)$ \\
\hline
\end{tabular}

Table 2 indicated the frequencies on each response categories by the interviews. Higher frequencies can be seen in aggression, conflict, burden, annoyance, worried, anxiety, overthinking, irritation, tension, and inability. Results reflected clear differences between girls and boys. Girls showed higher frequencies to express different emotions during frustration as compared to boys. These responses were further utilized to establish the item pool to develop a frustration scale for Pakistani emerging adults.

\section{DISCUSSION}

Frustration is one of the basic human behaviour. Everyone in society experiences frustration from birth to death. It is a natural phenomenon. Frustration is a common emotional response to opposition. Related to anger and disappointment, it arises from the perceived resistance to the fulfillment of individual will. The greater the obstruction, the greater the will, the more frustration is likely (Pramanik, 2016).

Every culture has unique ways to behave, and reacting to powerful emotions like frustration is handled differently (Woolman, 2020). Many quantitative kinds of research have investigated the reaction to frustration among adolescents (Biswas, 1989; Dangwal, 2000; Pramanik, 2016). Emotions of frustration are different according to the situation. In literature, no qualitative study found that investigated this phenomenon in emerging adults. So this study was intended to explore the construct of frustration qualitatively.

Qualitative analysis revealed some emotions related to frustration already existing in literature, i.e., aggression, conflict, anxiety, stress, helplessness, and loss of confidence (Akrani, 2011; Boll, 2017). The findings identified indigenous data that are somehow new to existing literature, including irritation, disappointment, loss of interest, sadness, instability, mental pressure, crying spells, upset, inability, etc.

First of all, most of the participants reported cognitive styles against frustration. Cognitive styles also affect the level of frustration. Participants reported different cognitive emotions like overthinking, tension, burden, loss of interest, negative thinking, and loss of confidence.

As one participant reported

"I feel upset and burden when I am in a state of frustration."

Another participant reported

"I start to think negatively about the event, and I lose my interest, and I felt overloaded as well."

A researcher like Harrington (2011) identified frustration intolerance cognitions lead to low self-confidence or perfectionistic cognitive styles. Increased frustration levels are linked to specific cognitions, including perceived lack of control (Brissett \& Nowicki, 1973), perceive unfairness (Cival, 2013), etc.

Participants also report effective emotions. Affective emotions include irritation, helplessness, disappointment, sadness, stress, crippledness, annoyance, worry, anxiety, hurts, and hopelessness.

As one participant reported

"I felt irritation and worried about my tasks when I could not achieve these goals timely."

One other participant reported

"I felt helpless and become disappointed when I am unable to do something."

Another participant also reported

"I become when someone breaks my trust, and I become anxious about my task."

These findings are also supported by previous literature (Calkin et al., 2002; Degnan et al., 2008), which indicated that frustration also affects our mood and thinking style (Harrigton, 2011). These findings are supported by previous literature (Powell et a., 2013) reported anxious, sadness, depression, and stress as an emotion commonly associated with frustration. Literature also demonstrates that perceived powerlessness, helplessness, and hopelessness are also associated with effective emotions of frustration (Lewandowski, 2003).

Emerging adults also reported behavioural emotions towards the frustrating situation. Behavioural emotions include aggression, withdrawal, fear, crying spell, instability, boredom, insecurity, and lack of tolerance. 
One participant reported

"I become more aggressive when I cannot complete my task or achieve my goal. This failure disturbs my functioning, and I lost my tolerance."

One other participant reported

"When I cannot be able to complete my task, then I leave it and take some time to do it with a new strategy."

Individuals show disruptive behaviour that often includes aggression and high frustration reactivity (Degnan et al., 2008; Eisenberg et al., 1994; Perry, 1977). Some individuals suffer from frustration intolerance, leaving them dysfunctional and unable or unwilling to work towards a personal goal and future endeavors (Boll, 2017; Harrington, 2011).

\section{CONCLUSION}

The present study was aimed to explore the phenomena of frustration from the perspective of emerging adults. Analysis of the transcripts revealed one main theme; emotions related to frustration, and three subthemes; Affective emotions, Cognitive styles, and Behavioral emotions. Frustration, like most behaviours, is influenced by both emotional and personal factors at the same time. This research has provided a comprehensive examination of anger conceptualization from the stance and experience of emerging adults, based on a probable description of frustration emotions founded on cognitive emotions, interpersonal emotions, and effective emotions. The results show frustration is a fundamental human emotion. All in society are angry from birth to death. This is a normal happening. The natural emotional effect of adversity is frustration. The indignation and resentment are related and stem from a so-called aversion to self-fulfillment. The more the obstacle and the greater the will, the greater the wrath.

\section{LIMITATIONS AND FUTURE RESEARCH}

While carrying out the current research, few limitations were also considered. There was a small sample size to conduct this research. Also, this research encompasses only major cities of Pakistan. Results for minor cities and remote areas could be different. The current study results highlight the importance of considering how young adults understand their conditions to help them regain functioning status and prevent missed developmental milestones for physicians dealing with emerging adults experiencing frustration. Besides, this research indicates to policymakers that the lack of optimism associated with anxiety disorders and inadequate access to and fragmentation of mental health services can substantially hinder these young adults' capacity to receive consistent, high-quality care. Preventive and recovery approaches should be tailored to meet the individual needs of today's frustrated young adults.

\section{ACKNOWLEDGEMENT}

We would like to thank all the independent reviewers of HSSR who conducted a feasibility study of our research work.

\section{AUTHORS CONTRIBUTION}

Aaliya Zaka and Dr. Iffat Rohail wrote the research paper and designed the organization of the article. Andleeb Akhtar, Hajra Aman, and Touseef Khalid performed the statistical analyses, interpretations, and technical parts. All the author(s) have a significant contribution to the research article.

\section{REFERENCES}

1. Akrani, G. (2011). Relationship between stress and job performance. Retrieved from http://kaylan_city.blogspo .com/2011/03/relationship between-stress_and_job.hotmail

2. Arnett, J. J. (2000). Emerging adulthood: A theory of development from the late teens through the twenties. American Psychologist, 55(5), 469-480. https://doi.org/10.1037/0003-066X.55.5.469

3. Arnett, J. J. (2016). College students as emerging adults: The developmental implications of the college context. Emerging Adulthood, 4, 219-222. https://doi.org/10.1177/2167696815587422

4. Arnett, J. J., \& Padilla-Walker, L. M. (2015). Brief report: Danish emerging adults' conceptions of adulthood. Journal of Adolescence, 38, 39-44. https://doi.org/10.1016/j.adolescence.2014.10.011

5. Aydın, G., \& Michou, A. (2020). Self-determined motivation and academic buoyancy as predictors of achievement in normative settings. British Journal of Educational Psychology,90(4), 964-980. https://doi.org/10.11 11/bjep.12338

6. Bernard, E. \& Ellis, A. (2006). Rational-emotive behavioral approaches to childhood disorder: History theory, practice and research. In Rational emotive behavioral approaches to childhood disorders. Springer. https://doi.org/10.1007/0-387-26375-6_1 
7. Bhutia,Y \& Sungho, B (2014). Adolescents of Shillong: Their reactions to frustration. International Journal of Education and Psychological Research, 3(1), 54-58.

8. Biswas, P.C (1989). Reaction to frustration in school children. Kalyani University.

9. Boll, J. (2017). Emerging adulthood and young adult mental health. https://www.rtor.org/emerging-adults/

10. Brisset, M \& Nowicki, S (1973). Internal versus external control of reinforcement and reaction to frustration. Journal of Personality and Social Psychology. 25(1), 35-44. https://doi.org/10.1037/h0034247

11. Calkins, S. D., Dedmon, S. E.,Gill, K. L., Lomax, L. E., \& Johnson, L. M. (2002). Frustration in Infancy: Implications for emotion regulation, physiological processes, and temperament. Infancy, 3(2), 175-197. https://doi.org/10.1207/S15327078IN0302_4

12. CAMHS Review (2008). Children and young people in mind: The Final Report of the National CAMHS Review. CAHMS.

13. Caterina, B., Filippello, P., Harrington, N., Costa, S., \& Sorrenti, L. (2018). Perceived parentral psychological control and school learned helplessness: The role of frustration intolerance as a mediator factor. School Psychology International, 34(4), 360-377. https://doi.org/10.1177/0143034318775140

14. Chatterjee. S. (2016). Frustration and aggression among adolescents. Indian Journal of Applied Research, 6(2), 2338.

15. Chen, B., Vansteenkiste, M., Beyers, W., Boone, L., Deci, E. L., Van der Kaap-Deeder, J., ... Verstuyf, J. (2015). Basic psychological need satisfaction, need frustration, and need strength across four cultures. Motivation and Emotion, 39(2), 216-236. https://doi.org/10.1007/s11031-014-9450-1

16. Cival, C. (2013). Rejecting unfairness emotion-driven reaction or cognitive heuristic? Frontiers in Human Neuroscience, 7, 126-128. https://doi.org/10.3389/fnhum.2013.00126

17. Costa, S., Ingoglia, S., Inguglia, C., Liga, F., Lo Coco, A., \& Larcan, R. (2018). Psychometric Evaluation of Basic Psychological Need Satisfaction and Frustration Scale (BPNSFS) in Italy. Measurement and Evaluation in Counseling and Development, 51(3), 193-206. https://doi.org/10.1080/07481756.2017.1347021

18. Costa, S., Ingoglia, S., Inguglia, C., Liga, F., Lo Coco, A., \& Larcan, R. (2017). Psychometric Evaluation of the Basic Psychological Need Satisfaction and Frustration Scale (BPNSFS) in Italy. Measurement and Evaluation in Counseling and Development, 51(3), 193-206. https://doi.org/10.1080/07481756.2017.1347021

19. Dangwal, K.L (2000). A study of the relationship of reaction to frustration and academic achievement of class 5 th students. Indian Journal of Educational Research, 19, 49-55.

20. Dave, V.J (2013). Construction and tryouts of frustration inventory for the students of secondary schools. Sayone Publishing House.

21. Degnan, K. A., Calkins, S. D., \& Keane, S. P. (2008). Profiles of disruptive behavior across early childhood: Contributions of frustration reactivity, physiological regulation, and maternal behavior. Child Development, 79(5), 1357-1376. https://doi.org/10.1111/j.1467-8624.2008.01193x

22. Denzin, N. K. \& Lincoln, Y. S. (2011). The SAGE handbook of qualitative research. Sage Publication.

23. Eisenberg, N. (2000). Emotion, regulation, and moral development. Annual Review of Psychology, 51(1), 665-697. https://doi.org/10.1146/annurer.psych.51.1.665

24. Fillauer, J. P., Bolden, J., Jacobson, M., Partlow, B. H., Benavides, A., \& Shultz, J. N. (2020). Examining the effects of frustration on working memory capacity. Applied Cognitive Psychology, 34(1), 50-63. https://doi.org/10.1002/acp.3587

25. Harrington, N. (2011). Frustration intolerance: Therapy issues and strategies. Journal of Rational Emotive and Cognitive Behavior Therapy, 29(1), 4-16. https://doi.org/10.1007/s10942-011-0126-4

26. Howitt, D. (2010). Introduction to qualitative methods in psychology. Prentice Hall.

27. Izard, C. E. (1993). Systems for motivation, cognitive and non-cognitive development. Psychology Review, 100, 6898.

28. Johansen, C. B., Rothmann, M. J., Andersen, A., Beck-Nielsen, H., \& Pouwer, F. (2020). The role of parental support for emerging adults with Type 1 diabetes: A scoping review. Pediatric diabetes, 21(6), 995-1030.

29. Kakkar, N. \& Jain, K. (2015). Frustration among the secondary school students in relation to their emotional maturity: A Study. Bhartiyan International Journal of Education and Research, 5(1), 1-10.

30. Kashyap, V. (1989). Psychological determinants of adolescent problems. NCERT.

31. Lewandowski, C.A (2003). organizational factors contributing to worker frustration: The precursor to burnout. Journal of Sociology and Social Welfare, 30(4), 175-185.

32. Liga, F., Ingoglia, S., Cuzzocrea, F., Inguglia, C., Costa, S., Lo Coco, A., \& Larcan, R. (2018). The Basic Psychological Need Satisfaction and Frustration Scale: Construct and Predictive Validity in the Italian Context. Journal of Personality Assessment, 1-11. https://doi.org/10.1080/00223891.2018.1504053

33. Morral, P (1996). Clinical sociology and the frustration of clients. Mental Nursing, 16(3); 24-27. 
34. Ozer, S., \& Schwartz, S. J. (2020). Academic motivation, life exploration, and psychological well-being among emerging adults in Denmark. Nordic Psychology, 72(3), 199-221.

35. Parmenter, J. G., Galliher, R. V., Yaugher, A. C., \& Maughan, A. D. (2020). Intersectionality and Identity Configurations: A Qualitative Study Exploring Sexual Identity Development Among Emerging Adults Within the United States. Emerging Adulthood.

36. Perry, D (1977). Reward-induced decreased play effects: Reattribution of motivation, competing responses, or avoding frustration? Child Development, 48(4), 1369-1374.

37. Powell, R. A., Symbaluk, D. G., \& Honey, P. L. (2013). Introduction to learning and behavior. Wadsworth.

38. Pramanik, B. R. (2016). Reactions to frustration of scheduled tribe secondary school children in the district of Purba Midnapur West Bengal: A survey. https://www.semanticscholar.org/paper/reaction to frustrat ion_of_scheduled_tribe_school_pramanik/bocac8f056@3085bb93c435cf54f61750c4b6d12\#paper_header

39. Rani, R. \& Deswal, Y. S. (2015). Relationship of frustration and academic achievement of adolescent of government and non-government senior secondary schools. Bhartitam International Journal of Education and Research. 4(2). http://www.gangainstituteofeducation.com/NewDocs/vol-4/issue-3/6.pdf

40. Reid, K., Flowers, P. \& Larkin, M. (2005). Interpretative phenomenology analysis: An overview and methodological review. The Psychologist, 18, 20-23.

41. Ryan, R. M. \& Deci, E. L. (2000). Self-determination theory and the facilitation of intrinsic motivation, social development, and well-being. American Psychologists, 55; 68-78. https://dooi.or/10.10371/0003-006x.55.1.68

42. Santurio, J. I. M., Fernández-Río, J., Estrada, J. A. C., \& González-Víllora, S. (2020). Connections between bullying victimization and satisfaction/frustration of adolescents' basic psychological needs. Revista de Psicodidáctica (English ed.), 25(2), 119-126. https://doi.org/10.1016/j.psicoe.2019.11.002

43. Sharma, S. (1992). A comparative study of problems of adolescents from the rural and urban backgrounds [M.Ed. Dissertation]. Punjab University, Chandigarh.

44. Smith, J.A. \& Osborn, M. (2008). Interpretative phenomenological analysis. In Smith, J.A. (Ed.), Qualitative psychology: A practical guide to methods. Sage

45. Stevenson, O., \& Parsloe, P. (1993). Community care \& frustration. Joseph Rowntree Foundation.

46. Vansteenkiste, M., \& Ryan, R. M. (2013). On psychological growth and vulnerability: Basic psychological need satisfaction and need frustration as a unifying principle. Journal of Psychotherapy Integration, 23(3), 263-280. https://doi.org/10.1037/a0032359

47. Woolmen, J. (2020). "No celebration": Indigenous communities, leaders share Canada day frustration. The University of British Columbia. www.irshdc.ubc.ca/2020/06/

48. Zimmerman, M. A. \& Rappaport, J. (1988). Citizen participation, perceived control, and psychological frustration. American Journal of Community Psychology, 16, 725-750. https://doi.org/10.1007/BF00930023 